\title{
Locally Advanced and Unresectable Cutaneous Squamous Cell Carcinoma: Outcomes of Concurrent Cetuximab and Radiotherapy
}

\author{
Robert M. Samstein, ${ }^{1}$ Alan L. Ho, ${ }^{2}$ Nancy Y. Lee, ${ }^{1}$ and Christopher A. Barker ${ }^{1}$ \\ ${ }^{1}$ Department of Radiation Oncology, Memorial Sloan Kettering Cancer Center, 1275 York Avenue, Box 22, New York, \\ NY 10065, USA \\ ${ }^{2}$ Department of Medicine, Memorial Sloan Kettering Cancer Center, New York, NY 10065, USA
}

Correspondence should be addressed to Christopher A. Barker; barkerc@mskcc.org

Received 18 June 2014; Accepted 2 July 2014; Published 21 July 2014

Academic Editor: Arash Kimyai-Asadi

Copyright @ 2014 Robert M. Samstein et al. This is an open access article distributed under the Creative Commons Attribution License, which permits unrestricted use, distribution, and reproduction in any medium, provided the original work is properly cited.

Background. Advanced age and immune dysfunction are risk factors for cutaneous squamous cell carcinoma (cSCC) and often render patients with locally-advanced disease medically inoperable or surgically unresectable, but potentially curable with radiotherapy. Concurrent chemotherapy and radiotherapy may not be well tolerated in this population, but another systemic therapy may improve disease control. Objective. Determine the tolerance and efficacy of concurrent cetuximab and radiotherapy (CRT) for patients with locally advanced and unresectable cSCC. Methods. Retrospective analysis of 12 patients treated with CRT for locally advanced and unresectable cSCC. Results. Patients were elderly and $75 \%$ had moderate-to-severe comorbidities, while $42 \%$ had immune dysfunction. Grades 3-4 adverse events were noted in $83 \%$ of patients; $67 \%$ required hospital admission for adverse events. Complete and partial response was noted in 36\% and $27 \%$ (response rate, $64 \%$ ). Stable and progressive disease was noted in 3 and 1 patients, respectively (disease control rate, 91\%). Median progression-free and overall survival were 6.4 and 8.0 months, respectively. Limitations. Retrospective small-cohort, single-institution analysis. Conclusion. Patients selected for CRT were elderly, with comorbidities and immune dysfunction, but treatment responses were observed. Patients selected for this treatment approach have a poor prognosis with limited capacity for therapy; more effective treatment is needed.

\section{Introduction}

Cutaneous squamous cell carcinoma (cSCC) is one of the most common cancers in the United States with an increasing incidence over the past few decades. The disease often presents at an early stage and is controlled with surgical, radiation, topical, or photodynamic therapy. Advanced age and immune dysfunction are risk factors for CSCC and render some patients medically unfit for surgery at diagnosis or recurrence. Moreover, some patients present with extensive local invasion or metastasis, rendering the cSCC surgically unresectable. Patients with locally advanced cSCC that are medically inoperable or surgically unresectable have a poor prognosis but can be cured with radiotherapy $[1,2]$.
Improving the outcome of radiotherapy through the use of concurrent systemic therapy has been demonstrated in several locally advanced cancer-treatment paradigms. Platinum (e.g., cisplatin, carboplatin) and halogenated pyrimidine (e.g., 5-fluorouracil) chemotherapies are frequently used in conjunction with radiotherapy to improve treatment efficacy but may not be well tolerated by patients of advanced age, or those who are immunosuppressed or harbor significant comorbidities [3]. For this particular patient population, a systemic therapy to combine with radiotherapy that is effective and well tolerated is needed.

Cetuximab (Erbitux, Genentech) is a monoclonal chimeric IgG1 antibody that binds and blocks the epidermal growth factor receptor (EGFR). EGFR, a transmembrane 
tyrosine kinase, has been shown to be upregulated in a variety of squamous cell carcinomas and its downstream antiapoptotic signaling cascade has been well studied [4]. In cSCC, series have reported EGFR overexpression in 43-100\% of patients studied [5-8], and overexpression appears to be more common in patients with metastasizing cSCC [9]. Reports from small clinical trials have indicated that cetuximab has activity in metastatic or unresectable cSCC, either alone or in combination with other therapies $[10,11]$.

Cetuximab has been approved by the Food and Drug Administration for use in combination with radiotherapy for mucosal squamous cell carcinoma of the head and neck based on a large randomized trial demonstrating improved survival compared with radiotherapy alone $[12,13]$. Cetuximab is thought to function as a radiosensitizer contributing to a synergistic effect when it is combined with radiotherapy [14]. The combination of cetuximab and radiotherapy (CRT) has also been tested in several other EGFR-expressing squamous cell carcinomas including lung, anal, esophageal, and uterine cervix squamous cell carcinoma [15-18]. There is little data available on the safety and effectiveness of CRT in patients with advanced cSCC. We thus sought to retrospectively study the toxicity and efficacy of combination CRT in patients with advanced cSCC treated at our institution.

\section{Methods}

2.1. Patients. Review of medical records was conducted with permission of the institutional review board (WA0552-11). Patients with cSCC that were selected for treatment with CRT were identified. Only patients that underwent concurrent treatment with both modalities were included in the study.

Patient demographics, comorbidities, and details of cSCC diagnosis and stage at the time of CRT were recorded. Comorbidities were classified according to the Adult Comorbidity Evaluation-27 (ACE-27). This system identifies 27 common medical ailments among 12 organ systems or disease processes and provides criteria to grade the comorbidity on a scale of $0-3$ ( 0 , ailment not present; 1 , mild decompensation; 2, moderate decompensation; 3, severe decompensation) [19]. Staging was performed according to the cutaneous squamous cell carcinoma system in the American Joint Committee on Cancer Staging Manual, version 7 [20].

2.2. Treatment and Adverse Events. Details of prior treatment including surgery, radiotherapy, and systemic therapy were reviewed and recorded. Common Terminology Criteria for Adverse Events version 4.0 (CTCAE v4.0) was used to assess, characterize, and grade adverse events observed during both cetuximab and radiotherapy [21].

2.3. Treatment Response. Treatment response within and outside the irradiated volume was assessed at the first posttreatment clinical and radiographic evaluations, 4-12 weeks after the completion of therapy. Formal imaging response assessment was not possible in some patients who were followed clinically (without imaging) after therapy and because of heterogeneous follow-up imaging. Operational definitions based on the Response Evaluation Criteria in Solid Tumors (RECIST) and PET Response Criteria in Solid Tumors (PERCIST) were used and included complete response (CR, disappearance of lesion), partial response (PR, $30 \%$ decrease in longest dimension of lesion), stable disease (SD, no evidence of response or progression), and progressive disease (PD, 20\% increase in longest dimension of the lesion). Overall and cSCC-specific survival were recorded.

2.4. Statistical Analysis. Kaplan-Meier curves were generated and used to estimate survival rates (with asymmetric 95\% confidence intervals) and median survival times and to compare between groups of patients. Statistical analysis was conducted using Graphpad Prism v6.0c.

\section{Results}

3.1. Patients. Twelve patients were selected for treatment with concurrent cetuximab and radiotherapy for locally advanced or unresectable cSCC between 2007 and 2013. Three patients were excluded from analysis: one received induction systemic therapy with cetuximab, carboplatin, and paclitaxel, followed by radiotherapy alone; two patients received palliative cetuximab for distant metastases and received a brief course of palliative radiotherapy directed at a site of distant metastasis. As detailed in Table 1, most patients were elderly (median age, 78 years; range, 47-90), all were white, and all but one was male. Median Karnofsky performance score was 80 (range, $50-90)$. Most patients had moderate $(42 \%)$ or severe $(33 \%)$ comorbidities. Almost half (42\%) of patients had identifiable immune dysfunction (chronic lymphocytic leukemia in 4, solid organ transplant in 1, and acquired immunodeficiency syndrome in 1 ).

The stage and presentation of cSCC is presented in Table 2. Most patients (75\%) received CRT for recurrent cSCC. All but two patients with known primary tumors (82\%) underwent excision; 4 of 9 patients had nodal recurrence after prior lymphadenectomy. No patients received prior chemotherapy for cSCC. All but one patient (who was given adjuvant CRT after surgical resection) had gross disease present at the start of treatment. All patients had locally advanced cSCC (T4 tumors) or regional nodal metastases. Two patients had distant metastases at the start of CRT.

3.2. Treatment and Adverse Events. All patients were treated with static-field intensity modulated radiation therapy using dynamic multileaf collimation. Treatment was delivered by a linear accelerator producing $6 \mathrm{MV}$ photons or $6-9 \mathrm{MeV}$ electrons, depending on the treatment target. One patient (number 3) was initially selected for concurrent cisplatin and radiotherapy but did not tolerate this and was switched to CRT. Conversely, one patient (number 6) was initially selected for CRT but did not tolerate this and was switched to carboplatin and paclitaxel concurrent with radiotherapy. The duration and relationship between cetuximab administration and radiotherapy are plotted in Figure 1. Radiation doses ranged between 12 and $80 \mathrm{~Gy}$ with a median dose of $60 \mathrm{~Gy}$ in 30 fractions (range, 3-38). Patients received cetuximab 
TABLE 1: Patient characteristics.

\begin{tabular}{|c|c|c|c|c|c|c|c|}
\hline Patient & Age & Sex & Race & $\begin{array}{c}\text { Overall comorbidity } \\
\text { severity }\end{array}$ & Moderate and severe comorbidities & KPS & $\begin{array}{c}\text { Immune } \\
\text { dysfunction }\end{array}$ \\
\hline 1 & 83 & $\mathrm{M}$ & $\mathrm{W}$ & Mild & & 80 & \\
\hline 2 & 82 & $\mathrm{~F}$ & $\mathrm{~W}$ & Mild & & 80 & CLL \\
\hline 3 & 70 & M & $\mathrm{W}$ & Moderate & Respiratory & 80 & \\
\hline 4 & 59 & $\mathrm{M}$ & $\mathrm{W}$ & Moderate & Cardiovascular (congestive heart failure, arrhythmia) & 70 & Heart transplant \\
\hline 5 & 78 & M & $\mathrm{W}$ & Moderate & Obesity & 80 & \\
\hline 6 & 85 & $\mathrm{M}$ & $\mathrm{W}$ & Moderate & Cardiovascular (arrhythmia) & 80 & \\
\hline 7 & 47 & $\mathrm{M}$ & $\mathrm{W}$ & Severe & Immunologic (AIDS) & 70 & AIDS \\
\hline 8 & 78 & $\mathrm{M}$ & $\mathrm{W}$ & Moderate & Malignancy (leukemia) & 70 & CLL \\
\hline 9 & 75 & M & $\mathrm{W}$ & Severe & Endocrine (diabetes), respiratory, malignancy (leukemia) & 90 & CLL \\
\hline 10 & 77 & $\mathrm{M}$ & $\mathrm{W}$ & Mild & & 80 & \\
\hline 11 & 90 & M & W & Severe & Malignancy (solid tumor) & 50 & \\
\hline 12 & 86 & $\mathrm{M}$ & $\mathrm{W}$ & Severe & Malignancy (solid tumor) & 60 & \\
\hline
\end{tabular}

Demographic, comorbidity, and immune system dysfunction for each of the patients $(n=12)$ studied.

KPS: Karnofsky performance status, M: male, F: female, W: white, CLL: chronic lymphocytic leukemia, and AIDS: acquired immunodeficiency syndrome.

TABLE 2: Disease characteristics and treatment response.

\begin{tabular}{|c|c|c|c|c|c|}
\hline Patient & Stage ${ }^{*}$ & Recurrent & $\begin{array}{c}\text { Gross } \\
\text { disease }\end{array}$ & $\begin{array}{c}\text { Posttreatment response within } \\
\text { the irradiated volume }\end{array}$ & $\begin{array}{c}\text { Months until PD (in or out of } \\
\text { irradiated volume) }\end{array}$ \\
\hline 1 & T4N2bM0 & No & Yes & PR & 6.4 (in) \\
\hline 2 & T0N2bM0 & Yes & Yes & $\mathrm{CR}$ & 14.7 (in), 16.3 (out) \\
\hline 3 & T0N2bM0R0 & Yes & No & $\mathrm{N} / \mathrm{A}$ & (Died with NED) \\
\hline 4 & T4N0M0 & Yes & Yes & SD & (Died without PD) \\
\hline 5 & T0N1M0 & Yes & Yes & CR & (Alive with NED) \\
\hline 6 & T4N0M0 & Yes & Yes & $\mathrm{SD}$ & (Alive with NED) \\
\hline 7 & $\mathrm{~T} 2 \mathrm{~N} 2 \mathrm{bM} 0$ & No & Yes & PD (during treatment) & 1.7 (in and out) \\
\hline 8 & T0N2bM1 & Yes & Yes & $\mathrm{CR}$ & 2.1 (out), 5.0 (in) \\
\hline 9 & $\mathrm{~T} 2 \mathrm{~N} 2 \mathrm{bM} 0$ & Yes & Yes & CR & 4.4 (out) \\
\hline 10 & T4N0M0 & Yes & Yes & $\mathrm{SD}$ & 52.2 (in) \\
\hline 11 & T0N3M1 & Yes & Yes & PR & 1.6 (out) \\
\hline 12 & T4N0M0 & No & Yes & PR & 4.4 (out), 4.7 (in) \\
\hline
\end{tabular}

Disease status at the start of therapy and investigator assessed response 4-12 weeks after therapy are presented.

${ }^{*}$ All patients were staged clinically, except patient 3 , who was staged pathologically.

PR: partial response, CR: complete response, SD: stable disease, PD: progressive disease, NED: no evidence of disease, IV: irradiated volume, and N/A: not applicable (because patient received adjuvant therapy [no measureable disease for response assessment]).

at $400 \mathrm{mg} / \mathrm{m}^{2}$, followed by weekly treatment at $250 \mathrm{mg} / \mathrm{m}^{2}$ through the end of radiotherapy, if they tolerated this treatment approach. Median cetuximab dose was $1525 \mathrm{mg} / \mathrm{m}^{2}$ (range, 400-2400). Treatment was delayed in 5 patients due to adverse events, and 2 patients had radiotherapy terminated early due to progression of disease. Eight patients were hospitalized during or soon after treatment. The frequency of grades 2-4 adverse events is shown in Table 3; no patient developed a grade 5 adverse event although $83 \%$ of patients experienced a grade 3 or higher event. The most common adverse events observed included fatigue, acneiform rash, radiation dermatitis, and infection.

3.3. Treatment Response. The best clinical response in the irradiated volume among the 11 patients treated for gross disease (i.e., not adjuvantly) was CR in 4 patients (36\%) and PR in 3 (27\%), for an overall response rate of $64 \%$ (95\% confidence interval, 35-92\%). Median time to progression within the irradiated volume for patients achieving CR and PR was 9.9 and 6.4 months, respectively. Within the irradiated volume, SD was noted in 3 patients and PD in another patient, for a disease-control rate (DCR) of $91 \%$ (95\% confidence interval, $74-100 \%$ ). Both of the patients with distant metastases at the start of CRT had PD outside of the irradiated volume. Among patients without distant metastases at the start of CRT, PD occurred within the irradiated volume in 5 and outside the irradiated volume in 4 . The patient treated with adjuvant CRT died 4.8 months after treatment of noncancer-related causes with no evidence of recurrent cSCC. 


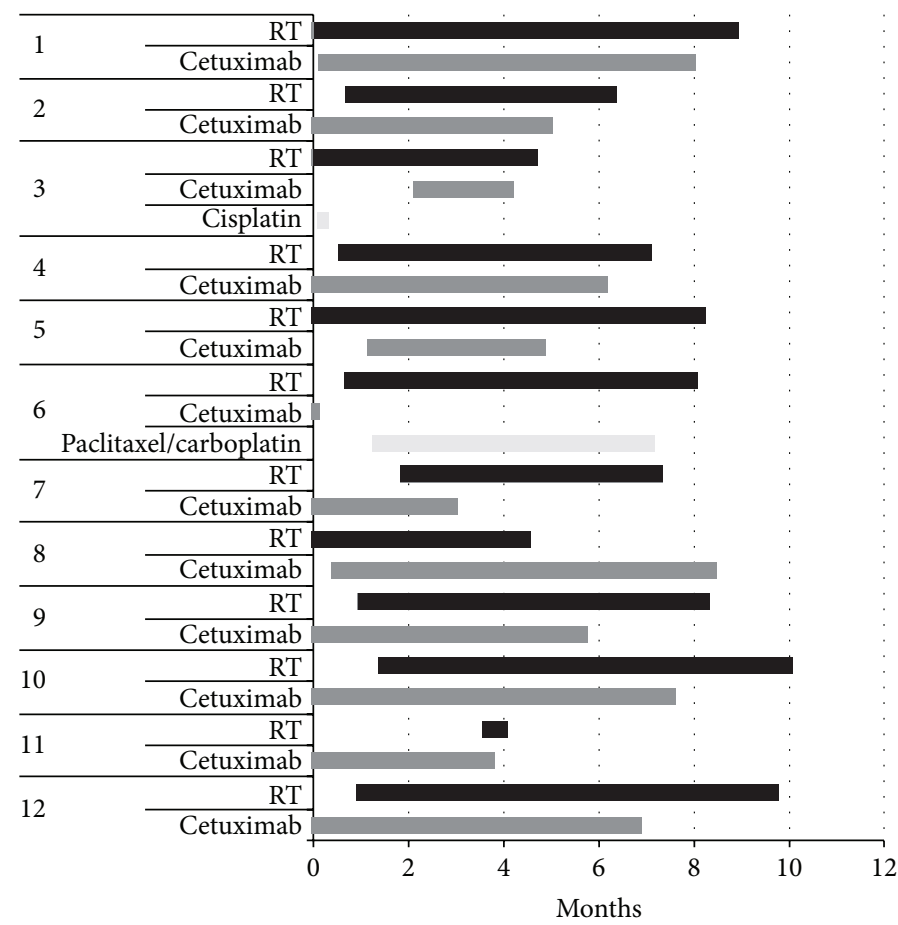

FIGURE 1: Relationship of cetuximab and radiotherapy. The duration of treatment and relationship in time for radiotherapy, cetuximab, and other systemic therapies is presented.

TABle 3: Grades 2-4 adverse events occurring during cetuximab and radiotherapy classified according to the Common Terminology Criteria for Adverse Events, version 4.0; no grade 5 adverse events were observed.

\begin{tabular}{lcccccc}
\hline \multirow{2}{*}{ Adverse event } & \multicolumn{2}{c}{ Grade 2 } & \multicolumn{2}{c}{ Grade 3 } & \multicolumn{2}{c}{ Grade 4 } \\
& $N$ & $(\%)$ & $N$ & $(\%)$ & $N$ & $(\%)$ \\
\hline Infusion reaction & 1 & $(8)$ & 0 & $(0)$ & 0 & $(0)$ \\
Acneiform rash & 5 & $(42)$ & 0 & $(0)$ & 0 & $(0)$ \\
Radiation dermatitis & 5 & $(42)$ & 3 & $(25)$ & 0 & $(0)$ \\
Mucositis & 3 & $(25)$ & 2 & $(17)$ & 0 & $(0)$ \\
Pneumonitis & 0 & $(0)$ & 1 & $(8)$ & 1 & $(8)$ \\
Anemia & 1 & $(8)$ & 1 & $(8)$ & 0 & $(0)$ \\
Thrombocytopenia & 1 & $(8)$ & 0 & $(0)$ & 0 & $(0)$ \\
Neutropenia & 0 & $(0)$ & 1 & $(8)$ & 0 & $(0)$ \\
Fatigue & 7 & $(58)$ & 1 & $(8)$ & 0 & $(0)$ \\
Weight loss & 2 & $(17)$ & 0 & $(0)$ & 0 & $(0)$ \\
Xerostomia & 2 & $(17)$ & 1 & $(8)$ & 0 & $(0)$ \\
Dysphagia & 3 & $(25)$ & 1 & $(8)$ & 0 & $(0)$ \\
Infection & 2 & $(17)$ & 3 & $(25)$ & 0 & $(0)$ \\
\hline
\end{tabular}

As noted in Figure 2, at the time of analysis, 7 of $12(58 \%)$ patients studied had died. Five of 7 (71\%) died of cSCC. Median follow-up for the entire cohort was 7.0 months but was 37.6 months for the 5 surviving patients. Median progression-free and overall survival were 6.4 and 7.95 months, respectively. Median cSCC-specific survival was not reached. cSCC-specific and overall survival were 51\% (95\% confidence interval, 26-85\%) and 40\% (95\% confidence

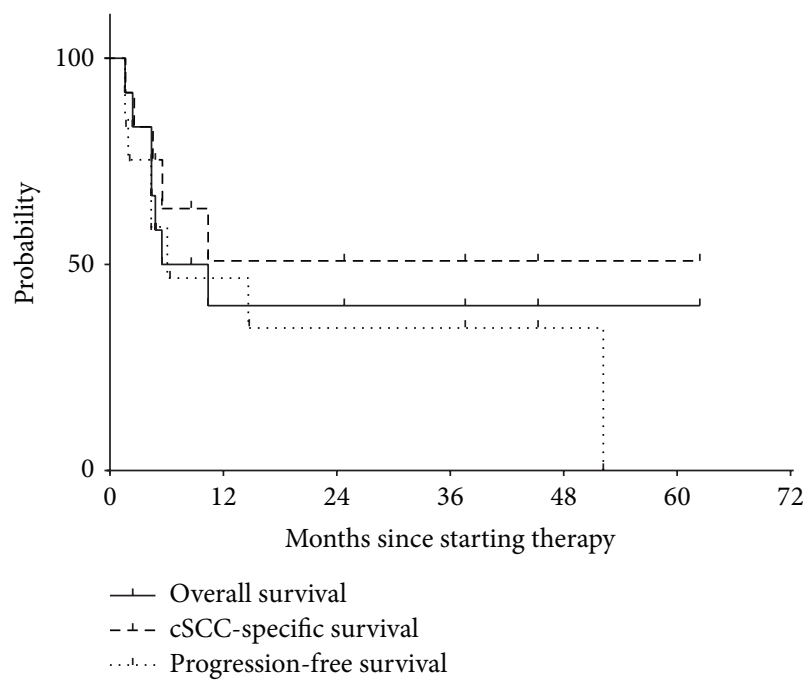

Figure 2: Overall, disease-specific, and progression-free survival. Median progression-free and overall survival were 6.4 and 8.0 months, respectively. Median cutaneous squamous cell carcinoma(cSCC-) specific survival was not reached. cSCC-specific and overall survival were $51 \%$ (95\% confidence interval, $26-85 \%$ ) and $40 \%(95 \%$ confidence interval, $14-66 \%)$ at 2 years.

interval, 14-66\%) at 2 years. Median progression-free and overall survival were 2.1 and 3.6 months in patients with distant metastases at the start of CRT compared with 14.7 and 10.4 without distant metastases, respectively. Median overall survival of patients with immune dysfunction was 4.4 
TABLE 4: Reported cases of cSCC treated with CRT.

\begin{tabular}{|c|c|c|c|c|c|c|c|c|c|}
\hline Study design & First author & $\begin{array}{c}\text { Publication } \\
\text { year }\end{array}$ & $\begin{array}{c}\text { Case } \\
\text { number }\end{array}$ & Age & Sex & $\begin{array}{c}\text { Radiotherapy } \\
\text { dose (Gy) }\end{array}$ & $\begin{array}{c}\text { Duration of } \\
\text { therapy (weeks) }\end{array}$ & Response & $\begin{array}{c}\text { Disease-free survival } \\
\text { (months) }\end{array}$ \\
\hline Case report & Kanakamedala MR & 2010 & - & 78 & $\mathrm{M}$ & $\mathrm{n} / \mathrm{r}$ & 8 & $\mathrm{CR}$ & 5 \\
\hline Case report & Goppner D & 2010 & - & 85 & $\mathrm{~F}$ & 45 & $\mathrm{n} / \mathrm{r}(<12)$ & $\mathrm{CR}$ & 14 \\
\hline Case report & Wollina U & 2011 & - & 77 & M & 60 & 6 & $\mathrm{CR}$ & 3 \\
\hline Case series & Giacchero D & 2011 & 2 & 67 & $\mathrm{M}$ & 50 & 7 & $\mathrm{CR}$ & 3 \\
\hline Case series & Giacchero D & 2011 & 3 & 72 & $\mathrm{M}$ & 60 & 7 & $\mathrm{CR}$ & 5 \\
\hline Case series & Giacchero D & 2011 & 4 & 79 & $\mathrm{M}$ & 70 & 18 & $\mathrm{CR}$ & 21 \\
\hline Case series & Giacchero D & 2011 & 8 & 78 & $\mathrm{M}$ & 70 & 7 & PR & $\mathrm{n} / \mathrm{r}$ \\
\hline Case series & Alter M & 2013 & 2 & 61 & M & 24 & 5 & $\mathrm{PR}$ & 5 \\
\hline Phase II trial & Preneau S & 2014 & 8 & 62 & $\mathrm{M}$ & $60-70$ & $\mathrm{n} / \mathrm{r}$ & $\mathrm{PR}$ & 8 \\
\hline Phase II trial & Preneau S & 2014 & 11 & 63 & $\mathrm{M}$ & $60-70$ & $\mathrm{n} / \mathrm{r}$ & PR & 8 \\
\hline Phase II trial & Preneau S & 2014 & 16 & 83 & $\mathrm{~F}$ & $60-70$ & $\mathrm{n} / \mathrm{r}$ & $\mathrm{PR}$ & 4 \\
\hline Phase II trial & Preneau S & 2014 & 17 & 86 & $\mathrm{~F}$ & $60-70$ & $\mathrm{n} / \mathrm{r}$ & $\mathrm{PR}$ & 5 \\
\hline Phase II trial & Preneau S & 2014 & 20 & 77 & M & $60-70$ & $\mathrm{n} / \mathrm{r}$ & $\mathrm{SD}$ & 5 \\
\hline
\end{tabular}

M: male, F: female, n/r: not reported, PR: partial response, CR: complete response, SD: stable disease, and PD: progressive disease.

months, while it was not reached among patients without immune dysfunction. Likewise, median survival of patients with moderate and severe comorbidities was 5.5 and 3.4 months, respectively, while it was not reached in patients with mild comorbidities.

\section{Discussion}

This study was designed to assess the efficacy and safety of the combination of cetuximab and radiotherapy in patients with advanced cSCC. We found that this treatment strategy yielded a response in $64 \%$ of patients, although disease progression after response was common and survival was limited. We found that patients selected for this treatment strategy were often elderly, with comorbidities and immune dysfunction. Despite the development of moderately severe adverse events, many patients required hospitalization in the period of time surrounding treatment. These results suggest that the patients we have selected for this treatment approach have a poor prognosis and limited capacity for therapy.

A multicenter phase II study of cetuximab monotherapy for unresectable cSCC was published in 2011. Thirty-six patients were accrued from 2005 to 2008, all of whom had performance status $\geq 2$ and no immune dysfunction. Median age of the group was 79 years (range, 32-95). Unresectable cSCC was present at the site of the primary tumor, regional lymph nodes, and distant metastasis in 47,44 , and $8 \%$ of the group, respectively. Six weeks after receiving cetuximab $\left(400 \mathrm{mg} / \mathrm{m}^{2}\right.$, then $250 \mathrm{mg} / \mathrm{m}^{2}$ weekly), $3 \%$ of patients had a CR, $8 \%$ of patients had a $\mathrm{PR}$, and $58 \%$ had SD, for a DCR of $69 \%$ (95\% confidence interval, 52-84\%). The best overall response rates were $\mathrm{CR}$ in $6 \%, \mathrm{PR}$ in $22 \%$ (response rate, $28 \%$; $95 \%$ confidence interval, $14-45 \%)$, and SD in 42\% (DCR, 69\%; 95\% confidence interval, 52-84\%). Median progression-free survival was 4.1 months (95\% CI $1.7-5$ months). Twenty-three patients (64\%) experienced a serious adverse event (grades 3-4). Acneiform rash (but not genetic polymorphisms) was associated with favorable progressionfree survival [10].

A single-center phase II study of cetuximab for unresectable cSCC was recently published. Among 20 patients accrued between 2009 and 2011, 5 were selected for treatment with radiotherapy (60-70 Gy) in conjunction with cetuximab ( $400 \mathrm{mg} / \mathrm{m}^{2}$, followed by $250 \mathrm{mg} / \mathrm{m}^{2}$ weekly for 3 weeks). One of the 5 patients receiving CRT was immunosuppressed, and the median age of this subgroup was 77 years. After 2 cycles of therapy ( 8 weeks) using RECIST criteria the authors observed no patient to have a CR, 4 of $5(80 \%)$ a PR, and 1 of 5 (20\%) SD, for a DCR of $100 \%$. Median progression-free survival was 5 months. Four (80\%) patients experienced a serious adverse event (grade 3-4). Patients selected to receive radiotherapy appeared to have a higher response rate (80\%) than patients selected to receive carboplatin with cetuximab (response rate, $44 \%$ ) or cetuximab alone (response rate, 33\%) [11].

Between 2010 and the present, we have identified 10 patients with cSCC treated with CRT and reported in the medical literature as case reports or small case series. Table 4 provides details of 8 of these patients, in addition to the 5 patients treated with CRT from the phase II trial noted above. The median age of patients is 77 years (range, 61-85). Immune dysfunction was present in at least 1 patient. All had recurrent, unresectable cSCC. Most patients received cetuximab $\left(400 \mathrm{mg} / \mathrm{m}^{2}\right.$, then $250 \mathrm{mg} / \mathrm{m}^{2}$ weekly) for a median of 7 weeks and median radiation dose was $60 \mathrm{~Gy}$. Six of eight (75\%) patients from case reports or series were reported to have a complete response, while 2 of $8(25 \%)$ were reported to have a partial response [22-26]. One patient treated for unresectable cSCC with CRT was described in another case series, but details were not reported [27]. Yet another case series reported a 62-year-old man treated with adjuvant CRT 
after resection of a locally advanced cSCC, with no evidence of recurrence 2 years after treatment [28].

The results of CRT described above are generally consistent with those in the present study. The studies have all reported groups of elderly patients, with a median age in the late eighth decade. Immune dysfunction was less common in the previously reported studies $(0-20 \%$ of patients), compared with the present analysis (46.1\%). Importantly, the prior studies of CRT did not report the presence of comorbidities, which were found to be moderate or severe in the majority (76\%) of patients studied. Disease stage (and, specifically, the presence of distant metastasis) varied across the studies and is likely to be associated with the outcome of treatment. For these reasons, comparing the present results to prior studies is challenging. Nevertheless, the observed response rate of $64 \%$ is similar to the subset of patients in the recently published phase II study (80\%).

Our study has several potential limitations. First, the number of patients studied was small $(n=12)$. However, to our knowledge, the present report is the largest singleinstitution experience of CRT of cSCC and nearly doubles the number of patients reported after treatment for cSCC with CRT in the medical literature. Second, the treatment approach varied among patients studied. This is a function of the extended time period during which this study took place, as well as the nuances of the specific patient and disease characteristics confronted by clinicians at our center. Nevertheless, cetuximab was given in a consistent fashion ( $400 \mathrm{mg} / \mathrm{m}^{2}$, followed by $250 \mathrm{mg} / \mathrm{m}^{2}$ weekly), and radiotherapy was generally given to curative doses in conventional fractionation (60-70 Gy in 30-35 fractions) using standard static-field intensity-modulated techniques. Third, the methods for assessing response were not standardized. However, all patients underwent clinical evaluation and imaging within a relatively limited window of time after the completion of treatment, consistent with the prospective studies on this subject. Finally, the retrospective nature of this study with inherent selection biases and lack of a control group limits the strength of the conclusions that can be made. This study should therefore be used to generate hypotheses for future testing.

\section{Conclusion}

Our study was designed to assess the safety and efficacy of CRT for patients with locally advanced or metastatic unresectable cSCC. We found that the treatment was delivered to a group of elderly patients with moderate-to-severe comorbidities who often harbored immune dysfunction. Nevertheless, the majority of patients exhibited response to treatment. However, progression of disease typically followed soon thereafter. Progression-free and overall survival were limited, probably as a cumulative result of advanced age, comorbidities, immune dysfunction, and advanced cancer. Additional studies are needed to further improve outcomes by reducing the morbidity and increasing the efficacy of treatment.

\author{
Abbreviations \\ ACE-27: Adult Comorbidity Evaluation-27 \\ CI: Confidence interval \\ CR: $\quad$ Complete response \\ CRT: Concurrent cetuximab and radiotherapy \\ cSCC: Cutaneous squamous cell carcinoma \\ CTCAE: Common Terminology Criteria for \\ Adverse Events \\ DCR: Disease control rate \\ EGFR: Epidermal growth factor receptor \\ PD: $\quad$ Progressive disease \\ PERCIST: PET Response Criteria in Solid Tumors \\ PR: $\quad$ Partial response \\ RECIST: Response Evaluation Criteria in Solid \\ Tumors \\ SD: $\quad$ Stable disease.
}

\section{Conflict of Interests}

The authors declare that there is no conflict of interests regarding the publication of this paper.

\section{Acknowledgment}

Part of this study was presented at the 2014 Multidisciplinary Head and Neck Symposium in Scottsdale, Arizona, February 20, 2014.

\section{References}

[1] M. Alam and D. Ratner, "Cutaneous squamous-cell carcinoma," The New England Journal of Medicine, vol. 344, no. 13, pp. 975$983,2001$.

[2] M. O. F. Al-Othman, W. M. Mendenhall, and R. J. Amdur, "Radiotherapy alone for clinical T4 skin carcinoma of the head and neck with surgery reserved for salvage," The American Journal of Otolaryngology-Head and Neck Medicine and Surgery, vol. 22, no. 6, pp. 387-390, 2001.

[3] T. Y. Seiwert, J. K. Salama, and E. E. Vokes, "The concurrent chemoradiation paradigm - general principles," Nature Clinical Practice Oncology, vol. 4, no. 2, pp. 86-100, 2007.

[4] N. Normanno, A. de Luca, C. Bianco et al., "Epidermal growth factor receptor (EGFR) signaling in cancer," Gene, vol. 366, no. 1, pp. 2-16, 2006.

[5] G. B. Fogarty, N. M. Conus, J. Chu, and G. McArthur, "Characterization of the expression and activation of the epidermal growth factor receptor in squamous cell carcinoma of the skin," British Journal of Dermatology, vol. 156, no. 1, pp. 92-98, 2007.

[6] P. Uribe and S. Gonzalez, "Epidermal growth factor receptor (EGFR) and squamous cell carcinoma of the skin: molecular bases for EGFR-targeted therapy," Pathology Research and Practice, vol. 207, no. 6, pp. 337-342, 2011.

[7] A. Toll, R. Salgado, M. Yébenes et al., "Epidermal growth factor receptor gene numerical aberrations are frequent events in actinic keratoses and invasive cutaneous squamous cell carcinomas," Experimental Dermatology, vol. 19, no. 2, pp. 151153,2010

[8] E. Maubec, P. Duvillard, V. Velasco, B. Crickx, and M. F. Avril, "Immunohistochemical analysis of EGFR and HER-2 in 
patients with metastatic squamous cell carcinoma of the skin," Anticancer Research, vol. 25, no. 2, pp. 1205-1210, 2005.

[9] S. Ch'ng, I. Low, D. Ng et al., "Epidermal growth factor receptor: a novel biomarker for aggressive head and neck cutaneous squamous cell carcinoma," Human Pathology, vol. 39, no. 3, pp. 344-349, 2008.

[10] E. Maubec, P. Petrow, I. Scheer-Senyarich et al., "Phase II study of cetuximab as first-line single-drug therapy in patients with unresectable squamous cell carcinoma of the skin," Journal of Clinical Oncology, vol. 29, no. 25, pp. 3419-3426, 2011.

[11] S. Preneau, E. Rio, A. Brocard et al., "Efficacy of cetuximab in the treatment of squamous cell carcinoma," The Journal of Dermatological Treatment, vol. 25, no. 5, pp. 424-427, 2014.

[12] J. A. Bonner, P. M. Harari, J. Giralt et al., "Radiotherapy plus cetuximab for squamous-cell carcinoma of the head and neck," The New England Journal of Medicine, vol. 354, no. 6, pp. 567578, 2006.

[13] J. A. Bonner, P. M. Harari, J. Giralt et al., "Radiotherapy plus cetuximab for locoregionally advanced head and neck cancer: 5-year survival data from a phase 3 randomised trial, and relation between cetuximab-induced rash and survival," The Lancet Oncology, vol. 11, no. 1, pp. 21-28, 2010.

[14] S. Huang, J. M. Bock, and P. M. Harari, "Epidermal growth factor receptor blockade with $\mathrm{C} 225$ modulates proliferation, apoptosis, and radiosensitivity in squamous cell carcinomas of the head and neck," Cancer Research, vol. 59, no. 8, pp. 19351940, 1999.

[15] G. R. Blumenschein Jr., R. Paulus, W. J. Curran et al., "Phase II study of cetuximab in combination with chemoradiation in patients with stage IIIA/B non-small-cell lung cancer: RTOG 0324," Journal of Clinical Oncology, vol. 29, no. 17, pp. 2312-2318, 2011.

[16] L. O. Olivatto, F. M. Vieira, B. V. Pereira et al., "Phase 1 study of cetuximab in combination with 5-fluorouracil, cisplatin, and radiotherapy in patients with locally advanced anal canal carcinoma," Cancer, vol. 119, no. 16, pp. 2973-2980, 2013.

[17] H. Safran, M. Suntharalingam, T. Dipetrillo et al., "Cetuximab with concurrent chemoradiation for esophagogastric cancer: assessment of toxicity," International Journal of Radiation Oncology Biology Physics, vol. 70, no. 2, pp. 391-395, 2008.

[18] K. N. Moore, M. W. Sill, D. S. Miller et al., "A phase i trial of tailored radiation therapy with concomitant cetuximab and cisplatin in the treatment of patients with cervical cancer: a gynecologic oncology group study," Gynecologic Oncology, vol. 127, no. 3, pp. 456-461, 2012.

[19] W. L. Read, R. M. Tierney, N. C. Page et al., "Differential prognostic impact of comorbidity," Journal of Clinical Oncology, vol. 22, no. 15, pp. 3099-3103, 2004.

[20] S. B. Edge and American Joint Committee on Cancer, AJCC Cancer Staging Manual, Springer, New York, NY, USA, 2010.

[21] National Cancer Institute (U.S.), Common Terminology Criteria for Adverse Events (CTCAE), U.S. Deptartment of Health and Human Services, National Institutes of Health, National Cancer Institute, Bethesda, Md, USA, 2009.

[22] M. R. Kanakamedala, S. Packianathan, and S. Vijayakumar, "Lack of Cetuximab induced skin toxicity in a previously irradiated field: case report and review of the literature," Radiation Oncology, vol. 5, no. 1, article 38, 2010.

[23] D. Göppner, S. Nekwasil, I. Franke, H. Gollnick, and M. Leverkus, "Successful combination therapy of a locally advanced squamous cell carcinoma of the skin with cetuximab and $\gamma$ irradiation," JDDG - Journal of the German Society of Dermatology, vol. 8, no. 10, pp. 826-828, 2010.

[24] U. Wollina, A. Schreiber, K. Merla, and G. Haroske, "Combined cetuximab and volumetric modulated arc-radiotherapy in advanced recurrent squamous cell carcinoma of the scalp," Dermatology Reports, vol. 3, no. 3, article e57, 2011.

[25] D. Giacchero, J. Barrière, K. Benezery et al., "Efficacy of cetuximab for unresectable or advanced cutaneous squamous cell carcinoma-a report of eight cases," Clinical Oncology, vol. 23, no. 10, pp. 716-718, 2011.

[26] M. Alter, I. Satzger, A. Mattern, A. Kapp, and R. Gutzmer, "Treatment of advanced cutaneous squamous cell carcinomas with epidermal growth factor receptor inhibitors," Dermatology, vol. 227, no. 4, pp. 289-294, 2013.

[27] S. J. Kalapurakal, J. Malone, K. T. Robbins, L. Buescher, J. Godwin, and K. Rao, "Cetuximab in refractory skin cancer treatment," Journal of Cancer, vol. 3, no. 1, pp. 257-261, 2012.

[28] K. O’Bryan, W. Sherman, G. W. Niedt et al., "An evolving paradigm for the workup and management of high-risk cutaneous squamous cell carcinoma," Journal of the American Academy of Dermatology, vol. 69, no. 4, pp. 595.e1-602.e1, 2013. 


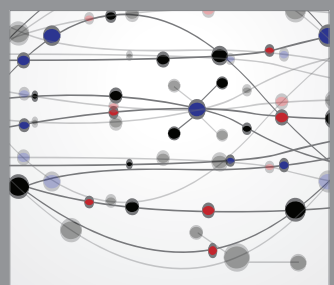

The Scientific World Journal
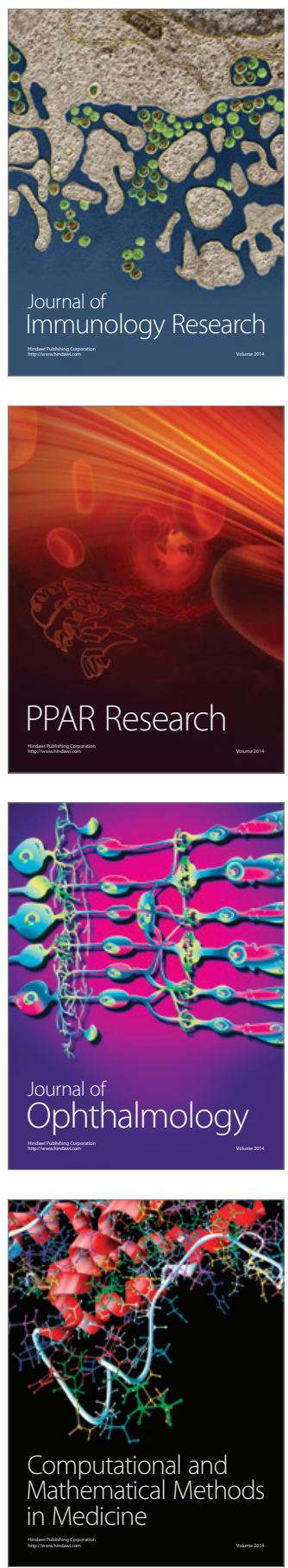

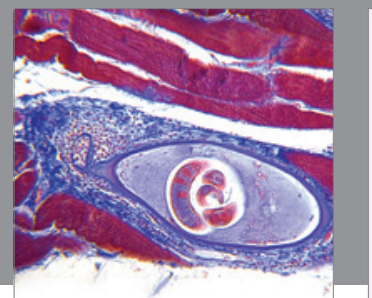

Gastroenterology

Research and Practice
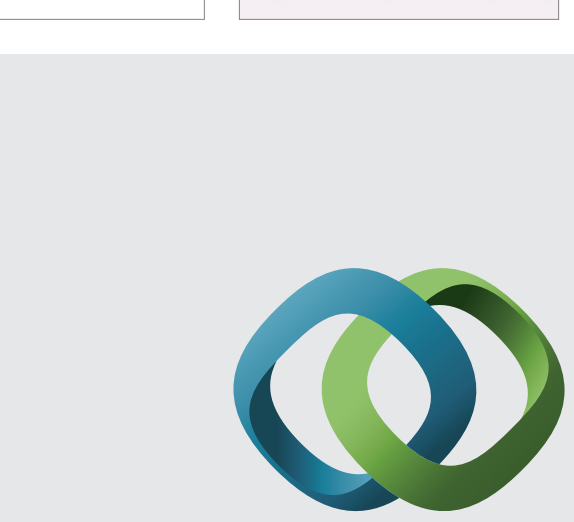

\section{Hindawi}

Submit your manuscripts at

http://www.hindawi.com
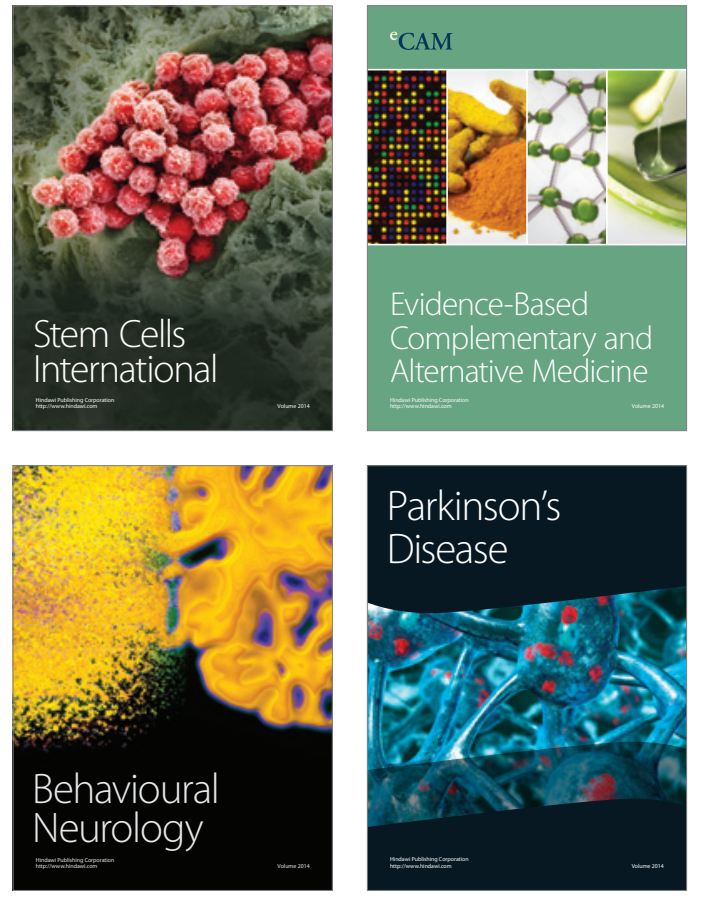
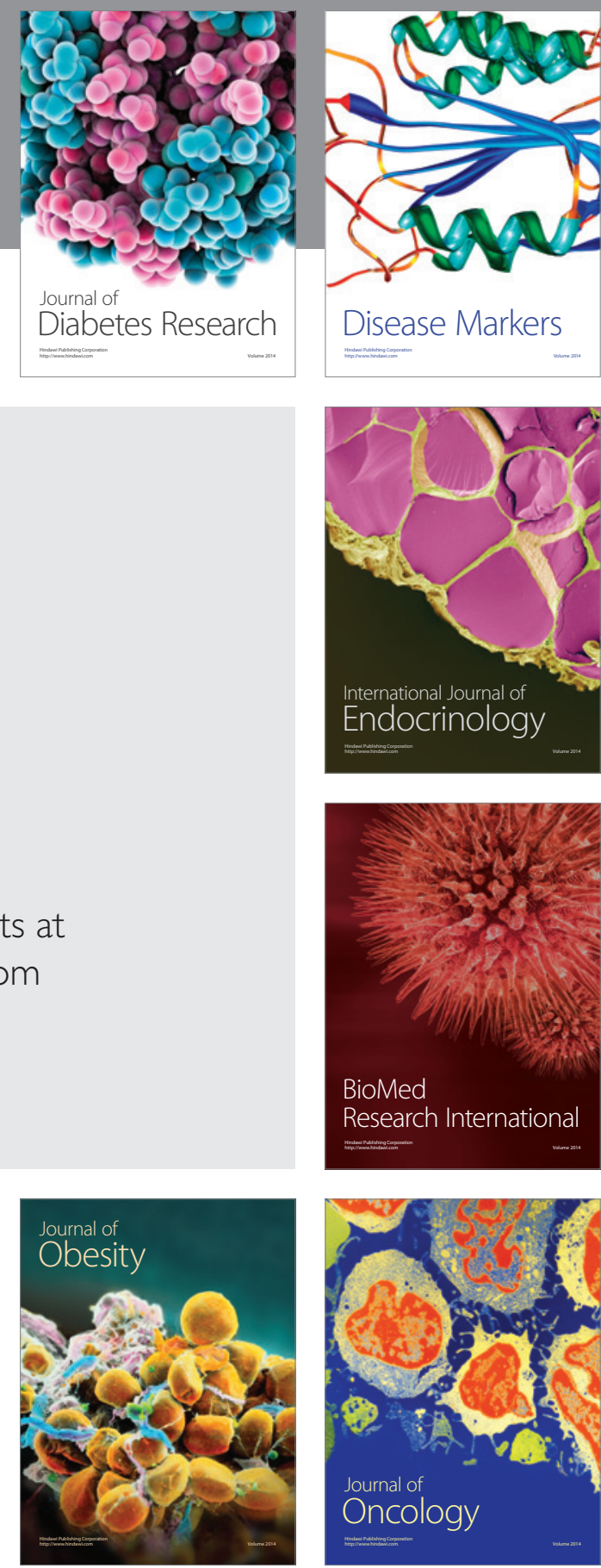

Disease Markers
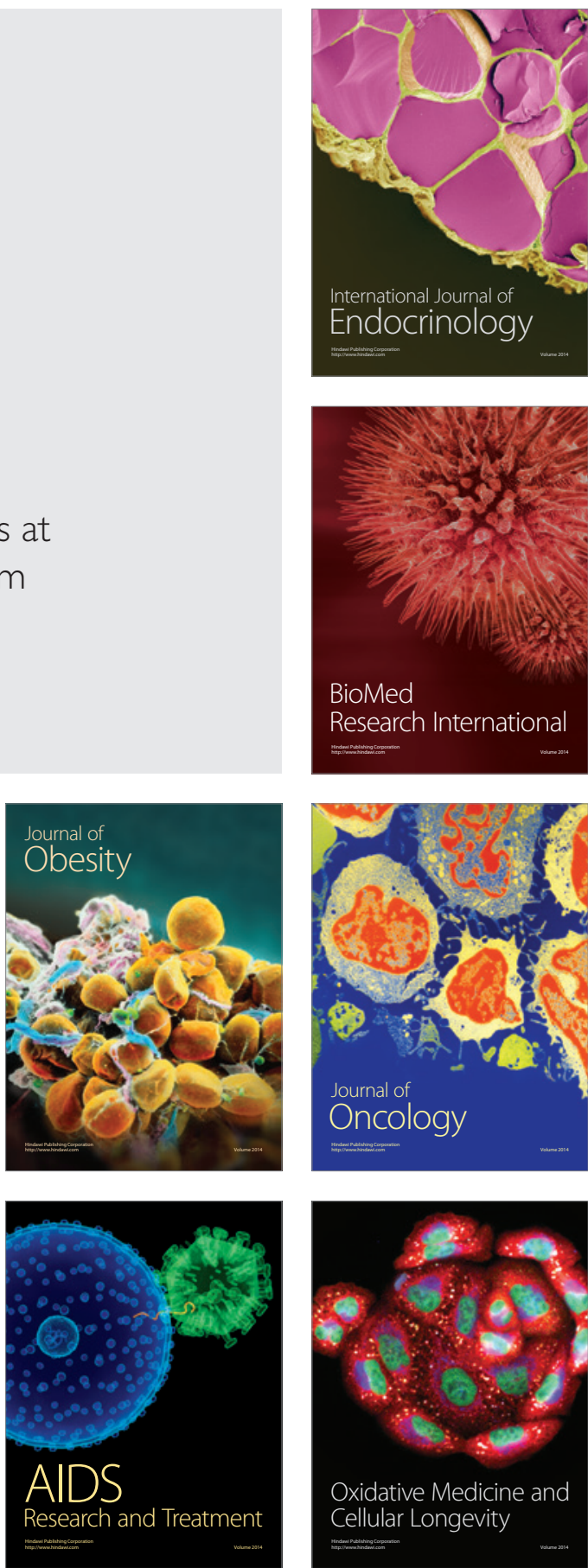